\title{
Factors affecting complications according to the modified Clavien classification in complete supine percutaneous nephrolithotomy
}

\author{
Siavash Falahatkar, MD; Keivan Gholamjani Moghaddam, MD; Ehsan Kazemnezhad, PhD; Alireza Farzan, MD; \\ Hamidreza Baghani Aval, MD; Ali Ghasemi, MD; Elaheh Shahab, MD; Seyednaser Seyed Esmaeili, MD; \\ Reza Motiee, MD; Seyedeh Alaleh Motiei Langroodi, MD; Mohadeseh Nemati, MD; Aliakbar Allahkhah, MD
}

Urology Research Center, Guilan University of Medical Sciences; and the Razi Hospital, Rasht, Iran

Cite as: Can Urol Assoc J 2015;9(1-2):e83-92. http://dx.doi.org/10.5489/cuaj.2248

Published online February 9, 2015.

\section{Abstract}

Introduction: An increase in percutaneous nephrolithotomy (PCNL) has been accompanied by an increase in complications. We identified the parameters affecting the severity of complications using the modified Clavien classification (MCC).

Methods: From 2008 to 2013, 330 patients underwent complete supine PCNL using subcostal access, one-shot dilation, rigid nephroscopy, and pneumatic lithotripsy. We assessed the impact of the following factors on complication severity based on the MCC: age, gender, body mass index, hypertension, diabetes, previous stone surgery and extracorporeal shock wave lithotripsy, preoperative hemoglobin, renal dysfunction (creatinine $>1.4 \mathrm{mg} / \mathrm{dL}$ ), preoperative urinary tract infection, anatomic upper urinary tract abnormality (AUUTA), significant (moderate-severe) hydronephrosis, stonerelated parameters (opacity, number, burden, location, staghorn, complex stones), anesthesia type, kidney side, imaging and calyx for access, tract number, tubeless approach, operative time, postoperative hemoglobin, and hemoglobin drop and stone-free results. Results: The complication rate was $19.7 \%$ (MCC: $0=80.3 \%$, $\mathrm{I}=6.4 \%, \mathrm{II}=11.2 \%, \geq \mathrm{II}=2.1 \%$ ). On univariate analyses, only the following factors affected MCC: gender, preoperative hemoglobin, AUUTA, significant hydronephrosis, imaging for access, calyx for access, tract number, postoperative hemoglobin, hemoglobin drop and stone-free result. Renal dysfunction was accompanied by higher complications, yet the results were not statistically significant. Multivariate logistic regression analysis demonstrated renal dysfunction, absence of significant hydronephrosis, AUUTA, multiple tracts, lower postoperative hemoglobin, and higher postoperative hemoglobin drop as the significant parameters which affected MCC and predicted higher grades. The paper's limitations include a low number of cases in the higher Clavien grades and some subgroups of variables, and not applying some techniques due to surgeon preference.

Interpretation: Many of the complete supine PCNL complications were in the lower Clavien grades and major complications were uncommon. Renal dysfunction, AUUTA, significant hydronephrosis, tract number, postoperative hemoglobin, and hemoglobin drop were the only factors affecting MCC.

\section{Introduction}

Presently, percutaneous nephrolithotomy (PCNL) is preferred as a safe and effective way to remove large or multiple upper urinary tract calculi. ${ }^{1-7}$ An increase in PCNL has been accompanied by variations in positions, techniques, and instruments, and these may have led to increased complications. ${ }^{1,2,4,5}$ Following PCNL, $79.5 \%$ of patients may experience an uncomplicated postoperative period, $, 8,8$ although there are reports of an early complication rate of $50.8 \%{ }^{4}$ PCNL complications may occur during puncturing, access, or stone removal. ${ }^{4} \mathrm{~A}$ standardized classification allow us to compare complications among different instruments, techniques, and centres. ${ }^{3,4,7,9}$ In 2004, the modified Clavien system (MCC) was introduced and allowed us to classify complications based on life-threatening conditions, interventions required, and disability. ${ }^{9}$ In recent years, this classification has been used to report PCNL complications instead of using

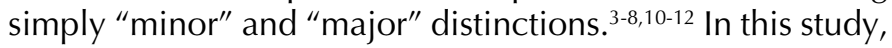
we reported on the PCNL complications according to the MCC and identified the parameters affecting the severity of complications based on this classification.

\section{Methods}

In a prospective analytical cross-sectional study, 330 patients with upper urinary tract stones underwent PCNL by 1 experienced surgeon from January 2008 to September 2013. We included patients with upper caliceal, middle caliceal and renal pelvic stones with stone burden $\geq 2 \mathrm{~cm}$, lower caliceal stones $\geq 1.5 \mathrm{~cm}$, upper ureteral stones $\geq 1 \mathrm{~cm}$, extracorporeal 
Falahatkar et al.

shock wave lithotripsy-resistant stones $\geq 1 \mathrm{~cm}$, multiple location stones with stone burden $\geq 2 \mathrm{~cm}$, and staghorn stones. We excluded patients with uncontrolled bleeding diathesis, untreated preoperative urinary tract infection (UTI), immunosuppression, and pregnant patients. Our ethics committee approved this study. Before surgery, we evaluated patients using blood cell count, coagulation tests, serum creatinine, urinalysis, urine culture, kidneys-ureters-bladder radiography, intravenous urography, ultrasonography, and computed tomography scan (in select cases). We considered preoperative serum creatinine $>1.4 \mathrm{mg} / \mathrm{dL}$ as renal dysfunction. Also staghorn and multiple locations stones, and moderate and severe hydronephrosis were considered as complex stones and significant hydronephrosis, respectively. If patients were taking antiplatelet drugs, these drugs were discontinued for 10 to 14 days before surgery. Patients with UTI were treated by appropriate antibiotic therapy before the PCNL. Also appropriate prophylactic antibiotics were administered for all patients before and after the operation. All PCNLs were performed with patients in the complete supine position ${ }^{13}$ due to the surgeon's experience. Compared with the prone $\mathrm{PCNL}$, the complete supine PCNL is a safe and effective procedure; patients do not need to be repositioned after intubation and catheterization. The complete supine position also allows us to control the airway appropriately during anesthesia and to sit during surgery. ${ }^{13}$ The procedure was initiated by cystoscopy and retrograde insertion of the ureteral stent and followed by puncturing the collecting system with an 18 -gauge needle and inserting a 0.035 -inch J-tip guidewire using the posterior subcostal access. A one-shot dilation technique (9-Fr dilator, 28-Fr Amplatz dilator), insertion of a 30-Fr Amplatz sheath (by possible and easy slipping and manipulating it over the 28-Fr Amplatz dilator into the collecting system), ${ }^{13,14}$ rigid nephroscopy, and pneumatic lithotripsy were performed. Multiple tracts and nephrostomy tube were used according to surgeon preference. After PCNL, the ureteral stent and Foley catheter were removed within 24 and 48 hours, unless patients had serious complications (i.e., significant blood loss or hematuria and leakage) necessitating irrigation or prolonged drainage. A blood transfusion was performed in patients with hemodynamic changes following blood loss or bleeding, especially in patients with postoperative hemoglobin less than $10 \mathrm{mg} / \mathrm{dL}$.

All patients were followed up to 3 months after surgery. We defined stone-free as the absence of stone fragments in intra-operative fluoroscopy or ultrasonography (and nephrostography in radiolucent stones) and in postoperative kidneys-ureters-bladder radiography and ultrasonography. We graded the complications according to severity using the MCC in 4 grades $(0, \mathrm{I}, \mathrm{II}, \geq \mathrm{III}$ ) (Table 1$) .{ }^{9}$ Grade 0 included patients without complications. All patients with the grades of IIla-V were classified as the grade $\geq$ III (major complications).

We assessed the impact of the following factors on com- plication severity based on the MCC: age, gender, body mass index (BMI), preoperative hemoglobin, renal dysfunction, preoperative UTI, hypertension, diabetes mellitus (DM), ischemic heart disease (IHD), previous stone surgery and extracorporeal shockwave lithotripsy (ESWL), anatomic upper urinary tract abnormality (AUUTA), significant hydronephrosis, stone-related parameters (number, burden, opacity, location, staghorn and complex stones), type of anesthesia, kidney side, imaging for access, calyx for access, tract number, tubeless approach, operative time, postoperative hemoglobin, postoperative hemoglobin drop, and stone-free result.

The SPSS version 16.0 software was used for data statistical analysis. The univariate analyses (Spearman test for quantitative variables, Mann-Whitney test for categorical variables, and Kruskal-Wallis test for qualitative variables with $>2$ categories) were used to evaluate the association between the above parameters and MCC. Also multivariate analysis using ordinal logistic regression was used to predict the factors affecting MCC and severity of complications (with control and adjustment of other variables). All $p$ values were two-tailed and $<0.05$ was considered statistically significant.

\begin{tabular}{|c|c|}
\hline Grade & Definition \\
\hline Grade I & $\begin{array}{l}\text { Any deviation from the normal postoperative course } \\
\text { without the need for pharmacological treatment or } \\
\text { surgical, endoscopic, and radiological interventions. } \\
\text { Allowed therapeutic regimens are: drugs as } \\
\text { antiemetics, antipyretics, analgesics, diuretics, } \\
\text { electrolytes, and physiotherapy. This grade also } \\
\text { includes wound infection opened at the bedsides. }\end{array}$ \\
\hline Grade II & $\begin{array}{l}\text { Requiring pharmacological treatment with other } \\
\text { than such allowed for grade I complications. Blood } \\
\text { transfusion and total parenteral nutrition are also } \\
\text { included. }\end{array}$ \\
\hline $\begin{array}{l}\text { Grade III } \\
\text { Grade IIla } \\
\text { Grade IIIb }\end{array}$ & $\begin{array}{l}\text { Requiring surgical, endoscopic or radiological } \\
\text { intervention } \\
\text { Intervention not under general anesthesia } \\
\text { Intervention under general anesthesia }\end{array}$ \\
\hline $\begin{array}{l}\text { Grade IV } \\
\text { Grade IVa } \\
\text { Grade IVb }\end{array}$ & $\begin{array}{l}\text { Life-threatening complication (including CNS } \\
\text { complications)* requiring IC/ICU management } \\
\text { Single organ dysfunction (including dialysis) } \\
\text { Multiorgan dysfunction }\end{array}$ \\
\hline Grade V & Death of a patient \\
\hline $\begin{array}{l}\text { Suffix } \\
\text { "d" }\end{array}$ & $\begin{array}{l}\text { If the patient suffers from a complication at the time } \\
\text { of discharge, the suffix " } d \text { " (for "disability") is added } \\
\text { to the respective grade of complication. This label } \\
\text { indicated the need for a follow-up to fully evaluate } \\
\text { the complication. }\end{array}$ \\
\hline
\end{tabular}

Adapted from Dindo et al. ${ }^{9}$ *Bain hemorrhage, ischemic stroke, subarachnoidal bleeding but excluding transient ischemic attacks. CNS: central nervous system; IC: intermediate care; ICU: intensive care unit. 


\section{Results}

The mean patient age was $49.38 \pm 12.63$. The mean stone burden was $35.11 \pm 17.09 \mathrm{~mm}$. The complication rate was $19.7 \%(n=65)$. The most common complications were blood transfusion and transient low-grade fever. Significant life-threatening bleeding, including gross hematuria, hematoma formation and hemoperitoneum, occurred in 15 patients $(4.5 \%)$, who were treated conservatively $(2.4 \%)$ or with interventions $(2.1 \%)$. The rates of the Clavien grades of $0, \mathrm{I}, \mathrm{II}, \mathrm{III}$, IV and V were $80.3 \%, 6.4 \%, 11.2 \%, 1.5 \%$, $0.3 \%$ and $0.3 \%$, respectively. Grade $\geq 11$ included 7 patients $(2.1 \%)$ (Table 2$)$. We also detailed patient complications, grading, and management (Table 3 ).

On univariate analysis, the following factors has no significant effect on MCC: age, BMI, preoperative UTI, hypertension, $\mathrm{DM}, \mathrm{IHD}$, previous stone surgery and ESWL, stone-related parameters, anesthesia type, kidney side, tubeless approach, and operative time. Although the group with renal dysfunction (grade 0: $66.7 \%$; grade I: $18.5 \%$; grade II: $14.8 \%$; grade

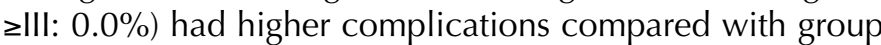
without renal dysfunction (grade 0: $81.5 \%$; grade I: $5.3 \%$; grade II: $10.9 \%$; grade $\geq$ III: $2.3 \%$ ), this difference was not significant $(p=0.111)$ in univariate analysis due to a lack of control or adjustment of other variables. The following all affected the MCC: gender $(p=0.040)$, upper tract abnormality $(p=0.002)$, significant hydronephrosis $(p<0.0001)$, imaging for access $(p=0.054)$, calyx for access $(p=0.019)$, tract number $(p=0.004)$, and stone-free result $(p=0.032)$. The groups with significant hydronephrosis, ultrasonography, and stonefree also had lower complications. The groups with upper tract abnormality, multiple calices, and multiple tracts accesses had significantly lower rates of grade 0 complications and higher rates of other grades compared with the groups without abnormality, single calyx, and single tract accesses. Each MCC grade had significantly different mean preoperative hemoglobin $(p=0.015)$, postoperative hemoglobin $(p<0.0001)$, and postoperative hemoglobin drop $(p<0.0001)$ (Table 4$)$.

In multivariate ordinal logistic regression analysis, anatomic upper tract abnormality (odds ratio [OR] 0.05), renal dysfunction (OR 0.32), the absence of significant hydronephrosis (OR 2.32), multiple tracts (OR 0.37), lower postoperative hemoglobin (OR 0.64), and higher postoperative hemoglobin drop (OR 1.57) were the significant parameters affecting MCC and predicting higher grades. We found that renal dysfunction, anatomic upper urinary tract abnormality, number of tract and postoperative hemoglobin protected this effect and prediction. A postoperative hemoglobin drop and significant hydronephrosis promoted the PCNL complication to a higher Clavien grade (Table 5).

\section{Discussion}

In PCNL, many complications are minor and their precise reporting is necessary, although major complications or death may occur. ${ }^{1-8,10,12}$ Compared with others studies, we had comparative results about complete supine PCNL complications according to the MCC. . $-8,10,12,15-17$ The types of complications, their management, and outcomes affect this classification. ${ }^{9,12}$ Therefore the MCC can be used to evaluate the severity of complications, yet it has its limitations. The MCC cannot predict the occurrence of a specific complication and cannot reveal its reason. Also due to different surgical managements, the subclassification of the higher Clavien grades has low reliability. If a single standardized manner is used for reporting and managing complications, the MCC can be applied to assess and compare PCNL complications at different centers or with techniques. ${ }^{12,18,19}$ Improvement in the management of complications and detection of the factors affecting MCC can influence the severity of complications. Age, gender, BMI, hypertension, DM, cardiovascular disease, previous kidney or stone treatment and surgery, prior ESWL, preoperative hematocrit and kidney side had no significant effect on the mean Clavien score, risk of grade $\geq$ Illa, major complications or complication rate. ${ }^{6,8,15,16,20-25}$ Some studies reported positive preoperative urine culture or pre-existent UTI as a significant parameter predicting complications. ${ }^{15,16,20}$ However, in other studies, positive urine culture had no significant effect on the mean Clavien score, grade $\geq$ Illa or complications in multivariate analysis. ${ }^{3,8,21}$ In our experience, age, gender, BMI, hypertension, DM, IHD, previous stone surgery and ESWL, preoperative hemoglobin, preoperative UTI and kidney side did not affect MCC. Positive preoperative urine culture does not predict urosepsis and systemic inflammatory response syndrome in PCNL. ${ }^{26,27}$ Although antibiotic prophylaxis can decrease infectious complications, ${ }^{28}$ the use of renal pelvic urine and stone cultures, and treatment of preoperative UTI should not be forgotten especially in patients with renal anomalies, hydronephrosis, large or staghorn stones and multiple tracts. ${ }^{26,27}$

One study reported no difference in the complication rates between groups with normal and impaired renal function. ${ }^{29}$ However, another study reported that chronic kidney disease stages had significantly different complication rates and Clavien scores, and decreased kidney function came with an increase in complication rates. ${ }^{30}$ In our study, renal dysfunction predicted complications and higher Clavien grades. Preoperative renal function may indeed predict PCNL complications and their severity.

Osther and colleagues reported similar complications and mean Clavien scores between groups with and without renal malformation. ${ }^{31}$ In children, renal anomalies and solitary 
Falahatkar et al.

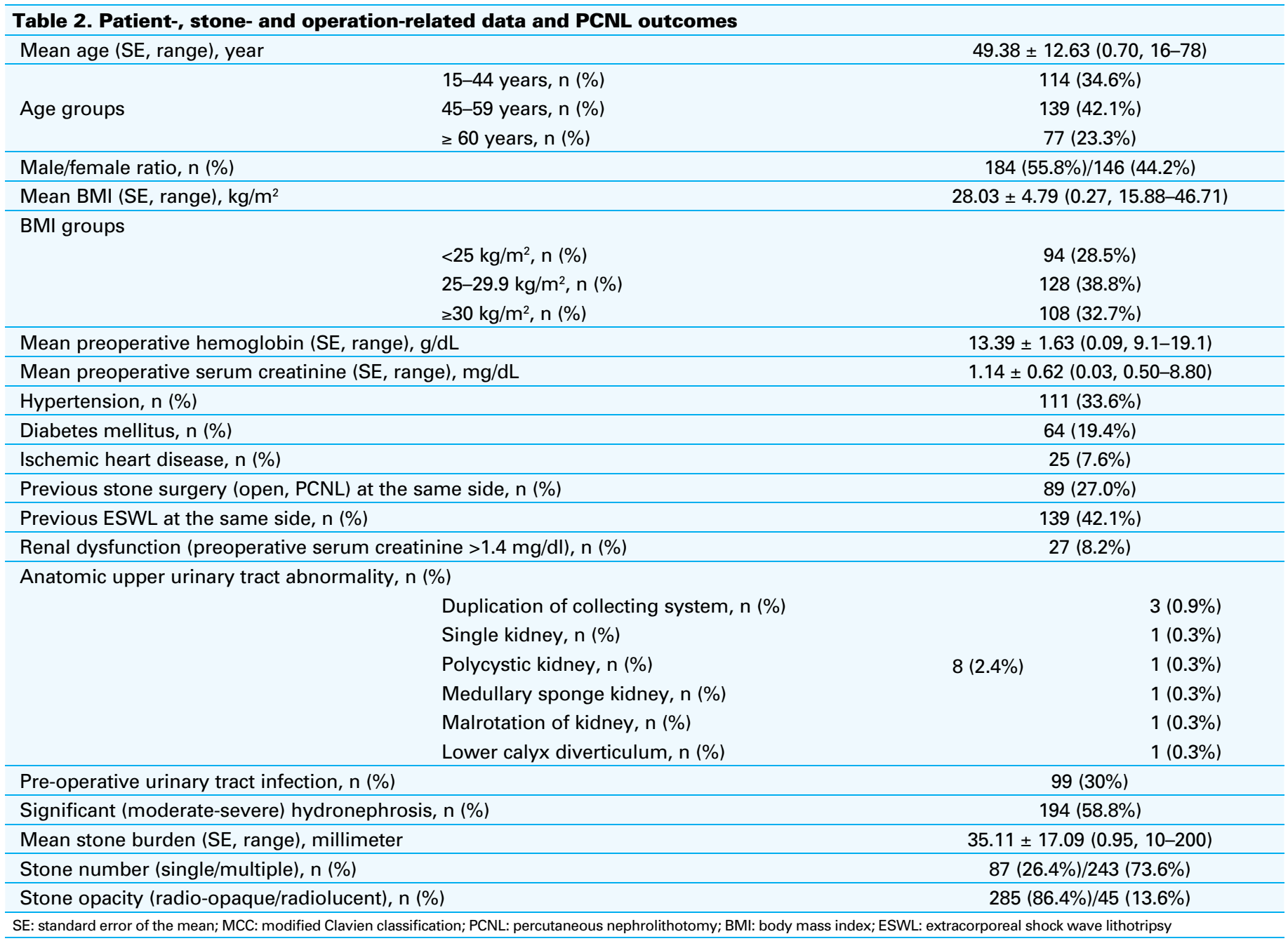

kidney had no significant effects on complication rates. ${ }^{21}$ In our study, anatomic upper urinary tract abnormalities significantly affected MCC and came with higher complications. The following factors may affect surgical techniques regarding access to the collecting system, manipulation and removal of stone and increase the complication rate: alteration in position and axis of the kidney, renal morphology, vasculature and mobility of the kidney, morphology of calices, pelvis and upper ureter. ${ }^{31,32}$ Laparoscopy, computed tomography or simultaneous use of fluoroscopy and ultrasonography might provide safe and easier access and manipulation in these cases. ${ }^{31-33}$ Also case volume, surgeon experience, and type of anomaly can affect the PCNL outcomes. $3,15,31,32$

Pre-existent hydronephrosis did not predict major complications in the Olbert study. ${ }^{20}$ Renal morphology (including hydronephrosis) had no significant effect on complications in staghorn stones. ${ }^{15}$ In our study, significant hydronephrosis predicted lower complications in MCC. An appropriate anatomic space facilitates calyx puncturing, access to the collecting system and stone manipulation, and reduces renal and pelvi-calyceal trauma and complications. ${ }^{32}$

Stone-related parameters (opacity, number, burden, location, staghorn and complex stones) did not affect MCC in our experience. In multiple studies, stone burden had no significant effect on the mean Clavien score, risk of grade $\geq$ Illa, major complications, or complication rate. ${ }^{8,15,16,20,21}$ In other studies, stone surface area or stone size significantly affected complications and mean Clavien score. ${ }^{3,17}$ Moreover, stone location, staghorn and complex stones had a significant influence on mean Clavien score, Clavien grades, or complications in some studies. $3,10,16,21,34$ In other studies, stone distribution and staghorn stone had no significant effect on complications or grade $\geq 11 \mathrm{la}$. ${ }^{6,17}$ Puncturing, access and stone removal largely affect PCNL complications. ${ }^{4}$ Stone characteristics may have eligible effects on the occurrence and severity of PCNL complications.

Multiple studies ${ }^{35-37}$ demonstrated comparative complication rates and Clavien classification of complications for general and spinal anesthesia similar to our results, although Cicek 


\begin{tabular}{|c|c|c|c|c|}
\hline \multirow{5}{*}{ Stone location } & \multicolumn{2}{|c|}{ Only one calyx, n (\%) } & \multicolumn{2}{|c|}{$71(21.5 \%)$} \\
\hline & \multicolumn{2}{|l|}{ Only pelvis, $\mathrm{n}(\%)$} & \multicolumn{2}{|c|}{$55(16.7 \%)$} \\
\hline & \multicolumn{2}{|c|}{ Only upper ureter, n (\%) } & \multicolumn{2}{|c|}{$8(2.4 \%)$} \\
\hline & \multicolumn{2}{|c|}{ Multiple locations, n (\%) } & \multicolumn{2}{|c|}{$163(49.4 \%)$} \\
\hline & \multicolumn{2}{|l|}{ Staghorn, n (\%) } & \multicolumn{2}{|c|}{$33(10.0 \%)$} \\
\hline \multicolumn{3}{|l|}{ Complex stones, n (\%) } & \multicolumn{2}{|c|}{$196(59.4 \%)$} \\
\hline \multirow{2}{*}{ Type of anesthesia } & \multicolumn{2}{|l|}{ General, n (\%) } & \multicolumn{2}{|c|}{$320(97.0 \%)$} \\
\hline & \multicolumn{2}{|l|}{ Spinal, n (\%) } & \multicolumn{2}{|c|}{$10(3.0 \%)$} \\
\hline \multicolumn{3}{|c|}{ Kidney side (right/left), n (\%) } & \multicolumn{2}{|c|}{$170(51.5 \%) / 160(48.5 \%)$} \\
\hline \multirow{2}{*}{ Imaging for access } & \multicolumn{2}{|l|}{ Fluoroscopy, n (\%) } & \multicolumn{2}{|c|}{$301(91.2 \%)$} \\
\hline & \multicolumn{2}{|c|}{ Ultrasonography, n (\%) } & \multicolumn{2}{|c|}{29 (8.8\%) } \\
\hline \multirow{4}{*}{ Calyx for access } & \multicolumn{2}{|c|}{ Upper calyx group, $\mathrm{n}(\%)$} & \multicolumn{2}{|c|}{$21(6.4 \%)$} \\
\hline & \multicolumn{2}{|c|}{ Middle calyx group, $\mathrm{n}(\%)$} & \multicolumn{2}{|c|}{$77(23.3 \%)$} \\
\hline & Lower calyx grou & & & \\
\hline & Multiple calices $\mathrm{g}$ & & & \\
\hline Number of tract (single & & & 300 & $9.1 \%)$ \\
\hline Tubeless approach (wit & e insertion), n (\%) & & & \\
\hline Mean operative time (S & & & $57.16 \pm$ & $10-195)$ \\
\hline Mean postoperative ho & day & & 2.23 & , 1-9) \\
\hline Mean postoperative hel & $\mathrm{g} / \mathrm{dL}$ & & $12.13 \pm$ & 7.0-16.5) \\
\hline Mean postoperative hel & ge), g/dL & & $1.27 \pm$ & $0.0-7.5)$ \\
\hline Stone freo recult & Stone-free, $\mathrm{n}(\%)$ & & & \\
\hline Stone-tree result & Residual fragmen & & & \\
\hline Success (stone-free or $r$ & $\mathrm{~nm}$ at one day afte & on), n (\%) & & \\
\hline Complication, n (\%) & & & & \\
\hline Blood transfusion, $\mathrm{n}(\%$ & & & & \\
\hline Transient low-grade fev & & & & \\
\hline Significant life-threaten & maturia, hematom & eritoneum), n (\%) & & \\
\hline & Grade $0, \mathrm{n}(\%)$ & & & \\
\hline & Grade I, n (\%) & & & \\
\hline MCC of comnlicatione & Grade II, n (\%) & & & \\
\hline 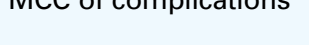 & & Grade III, n (\%) & & $5(1.5 \%)$ \\
\hline & Grade $\geq \mathrm{III}, \mathrm{n}(\%)$ & Grade IV, n (\%) & $7(2.1 \%)$ & $1(0.3 \%)$ \\
\hline & & Grade V, n (\%) & & $1(0.3 \%)$ \\
\hline
\end{tabular}

SE: standard error of the mean; MCC: modified Clavien classification; PCNL: percutaneous nephrolithotomy; BMI: body mass index; ESWL: extracorporeal shock wave lithotripsy

and colleagues reported higher minor complications (grades I-II), lower major complications (grades $\geq \mathrm{Illa}$ ), and lower rates of thce grades of II-IIIb and IVb for spinal anesthesia. ${ }^{35}$

We found that imaging for access did not affect MCC in multivariate analysis. Different studies demonstrated similar complications between ultrasonography and fluoroscopy, and imaging type had no significant effect on complication rates in children. ${ }^{21,38,39}$ Ultrasonography can be an appropriate alternative for fluoroscopy due to suitable outcomes, minimum radiation exposure, proper anatomical identification despite longer access and operative times, and the need for adequate skills or experience. ${ }^{32,33,38-40}$

In children, mid-calyceal puncture had a significant effect on complications. ${ }^{21}$ Shin and colleagues found that a punctured calyx did not predict grade $\geq 111$ la. ${ }^{6}$ Aron and colleagues reported similar complication rates for superior and inferior calyceal punctures in complex inferior calyceal stones. ${ }^{41}$ In another study, middle and lower calices accesses had similar complication rates and MCC. ${ }^{42}$ In our study, calyx for access did not predict MCC in multivariate analysis. If the calyx is selected for access based on renal anatomy, stone location, operation condition and surgeon preference, the safe and successful access and removal of stone can be achieved.

The meta-analysis study revealed no significant difference between tubeless and standard PCNL regarding complication rate. ${ }^{43}$ In our study, the tubeless approach had no significant effect on MCC.

There are different results about the effect of operative time on complications. ${ }^{3,6,8,16,21}$ Onal and colleagues found that operative time significantly affected the complication rate in children..$^{21}$ Labate and colleagues found that prolonged operative time significantly predicted a higher 
Table 3. MCC and managements of PCNL complications

\begin{tabular}{|c|c|c|c|}
\hline Type of complication & $\mathbf{N}(\%)$ & Clavien grade & Management \\
\hline Transient low-grade fever & $17(5.2 \%)$ & Grade I & Conservative management \\
\hline Bleeding requiring blood transfusion & $24(7.3 \%)$ & Grade II & Blood transfusion \\
\hline $\begin{array}{l}\text { Transient low-grade fever and bleeding requiring } \\
\text { blood transfusion }\end{array}$ & $6(1.8 \%)$ & Grade II & Conservative management for fever, blood transfusion \\
\hline Extravasation & $1(0.3 \%)$ & Grade I & WW and conservative management \\
\hline Bleeding requiring blood transfusion, extravasation & $1(0.3 \%)$ & Grade II & $\begin{array}{l}\text { Blood transfusion, WW and conservative management } \\
\text { for extravasation }\end{array}$ \\
\hline Gross hematuria & $3(0.9 \%)$ & Grade I & WW and conservative management \\
\hline $\begin{array}{l}\text { Gross hematuria, bleeding requiring blood } \\
\text { transfusion }\end{array}$ & $1(0.3 \%)$ & Grade II & $\begin{array}{l}\text { WW and conservative management for hematuria, } \\
\text { blood transfusion }\end{array}$ \\
\hline $\begin{array}{l}\text { Transient low-grade fever, gross hematuria, } \\
\text { bleeding requiring blood transfusion }\end{array}$ & $1(0.3 \%)$ & Grade II & $\begin{array}{l}\text { Conservative management for fever, WW and } \\
\text { conservative management for hematuria, blood } \\
\text { transfusion }\end{array}$ \\
\hline $\begin{array}{l}\text { Transient low-grade fever, bleeding requiring blood } \\
\text { transfusion, urinary leakage }\end{array}$ & $1(0.3 \%)$ & Grade II & $\begin{array}{l}\text { Blood transfusion, conservative management for fever, } \\
\text { WW and conservative management for urinary leakage }\end{array}$ \\
\hline $\begin{array}{l}\text { Gross hematuria, bladder retention with blood clot, } \\
\text { bleeding requiring blood transfusion }\end{array}$ & $1(0.3 \%)$ & Grade III & $\begin{array}{l}\text { WW and conservative management for hematuria, } \\
\text { bladder catheterization and multiple washouts/ } \\
\text { irrigations and removal of clots, blood transfusion }\end{array}$ \\
\hline $\begin{array}{l}\text { Gross hematuria, bladder retention with blood clot, } \\
\text { bleeding requiring blood transfusion }\end{array}$ & $1(0.3 \%)$ & Grade III & $\begin{array}{l}\text { WW and conservative management for hematuria, } \\
\text { bladder catheterization and multiple washouts/ } \\
\text { irrigations and removal of clots, blood transfusion, } \\
\text { angiography }\end{array}$ \\
\hline $\begin{array}{l}\text { Delayed gross hematuria, bleeding requiring blood } \\
\text { transfusion }\end{array}$ & $2(0.6 \%)$ & Grade II & $\begin{array}{l}\text { Watchful waiting and conservative management for } \\
\text { hematuria, blood transfusion }\end{array}$ \\
\hline $\begin{array}{l}\text { Delayed gross hematuria, bladder retention with } \\
\text { blood clot, ureteral obstruction with clot }\end{array}$ & 1 (0.3\%) & Grade III & $\begin{array}{l}\text { WW and conservative management for hematuria, } \\
\text { bladder catheterization and multiple washouts/ } \\
\text { irrigations and removal of clots, cystoscopy and } \\
\text { ureteric double-J stent insertion }\end{array}$ \\
\hline $\begin{array}{l}\text { Delayed recurrent gross hematuria, bladder } \\
\text { retention with blood clot, bleeding requiring blood } \\
\text { transfusion, interlobar artery pseudoaneurism of } \\
\text { lower pole of kidney }\end{array}$ & $1(0.3 \%)$ & Grade III & $\begin{array}{l}\text { Conservative management for hematuria, bladder } \\
\text { catheterization and multiple washouts/irrigations and } \\
\text { removal of clots, blood transfusion, angiography and } \\
\text { coil angioembolization }\end{array}$ \\
\hline $\begin{array}{l}\text { Gross hematuria, bladder retention with blood } \\
\text { clot, bleeding requiring blood transfusion, } \\
\text { retroperitoneal hematoma and renal vein } \\
\text { thrombosis }\end{array}$ & $1(0.3 \%)$ & Grade III & $\begin{array}{l}\text { Bladder catheterization and multiple washouts/ } \\
\text { irrigations and removal of clots, blood transfusion, } \\
\text { cystoscopy and ureteric double-J stent insertion, WW } \\
\text { and conservative management for hematuria and } \\
\text { hematoma and renal vein thrombosis }\end{array}$ \\
\hline $\begin{array}{l}\text { Perinephric hematoma, bleeding requiring blood } \\
\text { transfusion }\end{array}$ & $1(0.3 \%)$ & Grade II & $\begin{array}{l}\text { WW and conservative management for hematoma, } \\
\text { blood transfusion }\end{array}$ \\
\hline $\begin{array}{l}\text { Extravasation, delayed gross hematuria, bladder } \\
\text { retention with blood clot and organized hematoma } \\
\text { formation, ureteral obstruction with clot, bleeding } \\
\text { requiring blood transfusion, impaired renal function } \\
\text { (serum creatinine } 9.5 \mathrm{mg} / \mathrm{dL} \text { ) }\end{array}$ & $1(0.3 \%)$ & Grade IV & $\begin{array}{l}\text { WW and conservative management for extravasation } \\
\text { and hematuria, bladder catheterization and } \\
\text { multiple washouts/irrigations and removal of } \\
\text { clots and organized hematoma, cystoscopy and } \\
\text { ureteric double-J stent insertion, blood transfusion, } \\
\text { hemodialysis }\end{array}$ \\
\hline $\begin{array}{l}\text { Colon injury, hemoperitoneoum and bleeding } \\
\text { requiring blood transfusion leading to acute renal } \\
\text { failure and death }\end{array}$ & $1(0.3 \%)$ & Grade V & $\begin{array}{l}\text { Nephrectomy, blood transfusion, IV fluid and } \\
\text { antibiotics, ICU management }\end{array}$ \\
\hline
\end{tabular}

MCC: modified Clavien classification; PCNL: percutaneous nephrolithotomy; WW: watchful waiting; IV: intravenous; ICU: intensive care unit.

mean Clavien score and risk of grade $\geq \mathrm{IIla} .{ }^{8}$ However, operative time did not predict grade $\geq$ Illa or complications in others studies. ${ }^{3,6,16}$ In our study, operative time did not affect MCC. All PCNLs were performed by a single experienced endourologist. The learning curve and experi- ence can affect performance of access, operative time, and complications. . $^{3,15,18}$

Hegarty and colleagues reported similar complication rates for single tract and multiple tracts accesses without consideration of transfusion. ${ }^{44}$ Multi-puncture was not a significant 


\begin{tabular}{|c|c|c|c|c|c|c|}
\hline \multicolumn{2}{|l|}{ Parameter } & Grade 0 & Grade I & Grade II & Grade $\geq$ III & $p$ value \\
\hline \multicolumn{2}{|c|}{ Mean age (SE, range), year } & $\begin{array}{l}49.64 \pm 12.79 \\
(0.80,16-78)\end{array}$ & $\begin{array}{l}45.43 \pm 10.42 \\
(2.27,26-66)\end{array}$ & $\begin{array}{l}49.05 \pm 12.21 \\
(2.01,26-75)\end{array}$ & $\begin{array}{l}53.29 \pm 14.76 \\
(5.58,27-70)\end{array}$ & $0.471^{\dagger}$ \\
\hline \multirow{3}{*}{$\begin{array}{l}\text { Age grouping, years, } \\
\mathrm{n}(\%)\end{array}$} & $15-44$ & $88(77.2 \%)$ & $9(7.9 \%)$ & $15(13.2 \%)$ & $2(1.7 \%)$ & \multirow{3}{*}{$0.582 \S$} \\
\hline & $45-59$ & $112(80.6 \%)$ & $11(7.9 \%)$ & $15(10.8 \%)$ & $1(0.7 \%)$ & \\
\hline & $\geq 60$ & $65(84.4 \%)$ & $1(1.3 \%)$ & $7(9.1 \%)$ & $4(5.2 \%)$ & \\
\hline \multirow{2}{*}{ Gender, n (\%) } & Male & $155(84.2 \%)$ & $11(6.0 \%)$ & $14(7.6 \%)$ & $4(2.2 \%)$ & \multirow{2}{*}{$0.040 \ddagger$} \\
\hline & Female & $110(75.3 \%)$ & $10(6.8 \%)$ & $23(15.8 \%)$ & $3(2.1 \%)$ & \\
\hline \multicolumn{2}{|c|}{ Mean BMI (SE, range), kg/m² } & $\begin{array}{c}28.14 \pm 4.93 \\
(0.31,15.88-46.71)\end{array}$ & $\begin{array}{c}27.15 \pm 3.70 \\
(0.81,20.95-36.99)\end{array}$ & $\begin{array}{c}27.29 \pm 4.49 \\
(0.76,18.60-37.11)\end{array}$ & $\begin{array}{c}30.63 \pm 2.85 \\
(1.16,28.34-36.20)\end{array}$ & $0.476^{\dagger}$ \\
\hline \multirow{3}{*}{ BMI grouping, n (\%) } & $<25 \mathrm{~kg} / \mathrm{m}^{2}$ & $78(83.0 \%)$ & $6(6.4 \%)$ & $10(10.6 \%)$ & $0(0.0 \%)$ & \multirow{3}{*}{$0.238^{\S}$} \\
\hline & $25-29.9 \mathrm{~kg} / \mathrm{m}^{2}$ & $97(75.8 \%)$ & $10(7.8 \%)$ & $16(12.5 \%)$ & $5(3.9 \%)$ & \\
\hline & $\begin{array}{c}\geq 30 \mathrm{~kg} / \mathrm{m}^{2} \\
\text { (obese) }\end{array}$ & $90(83.3 \%)$ & $5(4.6 \%)$ & $11(10.2 \%)$ & $2(1.9 \%)$ & \\
\hline \multicolumn{2}{|c|}{$\begin{array}{l}\text { Mean preoperative hemoglobin } \\
\text { (SE, range), g/dL }\end{array}$} & $\begin{array}{c}13.49 \pm 1.51 \\
(0.09,9.6-18.0)\end{array}$ & $\begin{array}{c}13.71 \pm 2.18 \\
(0.47,9.1-19.1) \\
\end{array}$ & $\begin{array}{c}12.39 \pm 1.79 \\
(0.30,9.2-16.5)\end{array}$ & $\begin{array}{c}13.55 \pm 1.92 \\
(0.78,10.0-15.4)\end{array}$ & $0.015^{\dagger}$ \\
\hline \multirow{2}{*}{ Hypertension, n (\%) } & Yes & $89(80.2 \%)$ & $7(6.3 \%)$ & $10(9.0 \%)$ & $5(4.5 \%)$ & \multirow{2}{*}{$0.883^{\ddagger}$} \\
\hline & No & $176(80.4 \%)$ & $14(6.4 \%)$ & $27(12.3 \%)$ & $2(0.9 \%)$ & \\
\hline \multirow{2}{*}{$\mathrm{DM}, \mathrm{n}(\%)$} & Yes & $54(84.4 \%)$ & $4(6.2 \%)$ & $5(7.8 \%)$ & $1(1.6 \%)$ & \multirow{2}{*}{$0.339^{\prime}$} \\
\hline & No & $211(79.3 \%)$ & $17(6.4 \%)$ & $32(12.0 \%)$ & $6(2.3 \%)$ & \\
\hline \multirow{2}{*}{ IHD, n (\%) } & Yes & $20(80.0 \%)$ & $1(4.0 \%)$ & $1(4.0 \%)$ & $3(12.0 \%)$ & \multirow{2}{*}{$0.790^{\ddagger}$} \\
\hline & No & $245(80.3 \%)$ & $20(6.6 \%)$ & $36(11.8 \%)$ & $4(1.3 \%)$ & \\
\hline \multirow{2}{*}{$\begin{array}{l}\text { Renal dysfunction } \\
\text { (serum } \mathrm{Cr}>1.4 \mathrm{mg} / \mathrm{dL} \text {, } \\
\mathrm{n}(\%)\end{array}$} & Yes & $18(66.7 \%)$ & $5(18.5 \%)$ & $4(14.8 \%)$ & $0(0.0 \%)$ & \multirow[b]{2}{*}{$0.111^{\ddagger}$} \\
\hline & No & $247(81.5 \%)$ & $16(5.3 \%)$ & $33(10.9 \%)$ & $7(2.3 \%)$ & \\
\hline \multirow{2}{*}{$\begin{array}{l}\text { Anatomic upper urinary } \\
\text { tract abnormality, n (\%) }\end{array}$} & Yes & $3(37.5 \%)$ & $2(25.0 \%)$ & $1(12.5 \%)$ & $2(25.0 \%)$ & \multirow{2}{*}{$0.002^{\ddagger}$} \\
\hline & No & $262(81.4 \%)$ & $19(5.9 \%)$ & $36(11.2 \%)$ & $5(1.5 \%)$ & \\
\hline \multirow{2}{*}{ Preoperative UTI, n (\%) } & Yes & $82(82.8 \%)$ & $10(10.1 \%)$ & $3(3.0 \%)$ & $4(4.1 \%)$ & \multirow{2}{*}{$0.368^{\ddagger}$} \\
\hline & & $183(79.2 \%)$ & $11(4.8 \%)$ & $34(14.7 \%)$ & $3(1.3 \%)$ & \\
\hline \multirow{2}{*}{$\begin{array}{l}\text { Previous stone surgery, } \\
\mathrm{n}(\%)\end{array}$} & Yes & $69(77.5 \%)$ & $6(6.7 \%)$ & $11(12.4 \%)$ & $3(3.4 \%)$ & \multirow{2}{*}{$0.410^{\ddagger}$} \\
\hline & No & $196(81.3 \%)$ & $15(6.2 \%)$ & $26(10.8 \%)$ & $4(1.7 \%)$ & \\
\hline \multirow{2}{*}{ Previous ESWL, n (\%) } & Yes & $113(81.3 \%)$ & $10(7.2 \%)$ & $13(9.3 \%)$ & $3(2.2 \%)$ & \multirow{2}{*}{$0.650^{\ddagger}$} \\
\hline & No & $152(79.6 \%)$ & $11(5.7 \%)$ & $24(12.6 \%)$ & $4(2.1 \%)$ & \\
\hline \multirow{2}{*}{ Stone number, n (\%) } & Single & $72(82.8 \%)$ & $4(4.6 \%)$ & $9(10.3 \%)$ & $2(2.3 \%)$ & \multirow{2}{*}{$0.546^{\ddagger}$} \\
\hline & & $193(79.4 \%)$ & $17(7.0 \%)$ & $28(11.5 \%)$ & $5(2.1 \%)$ & \\
\hline
\end{tabular}

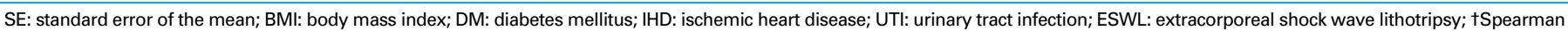
test; ¥Mann-Whitney test; §Kruskal-Wallis test.

factor predicting grade $\geq 11$ la. ${ }^{6}$ Tract number ${ }^{15,21}$ had no significant effect on complications in staghorn stones or children. But Netto and colleagues reported higher complication rates for multiple accesses versus upper pole and lower/middle calices accesses in staghorn stones..$^{45}$ In our experience, multiple tracts predicted higher complications in MCC. Many of our complications were related to vascular events, bleeding, and transfusion. The multiple tracts approach comes with increased blood loss and transfusion. ${ }^{46,47}$

In Onal study, postoperative hematocrit had no significant effect on complication rate in children. ${ }^{21}$ In our experience, postoperative hemoglobin and hemoglobin drop significantly affected MCC. Most of our complications were bleeding events. Lower postoperative hemoglobin and higher postoperative hemoglobin drop can imply serious injury to the vascular system or parenchyma and predict increased Clavien grades.

Similarly, the success or stone-free status affected complications in the Onal ${ }^{21}$ study and the group with residual fragments also had higher complications in univariate analysis. The PCNL complication was an outcome independent of the PCNL success. In multivariate analysis, the success had no significant effect on complication rates in children. ${ }^{21}$ Similarly, the stone-free result did not predict complications based on MCC in multivariate analysis in our study.

Our study has its limitations. Although we included all cases during the study period, we had low number of cases in the higher Clavien grades and some subgroups of variables. Also some techniques were not used due to surgeon. We did not assess the following factors that may affect 
Falahatkar et al.

\begin{tabular}{|c|c|c|c|c|c|c|}
\hline \multicolumn{2}{|l|}{ Parameter } & Grade 0 & Grade I & Grade II & Grade $\geq$ III & $p$ value \\
\hline \multicolumn{2}{|c|}{ Mean stone burden (SE, range), $\mathrm{mm}$} & $\begin{array}{c}34.97 \pm 17.26 \\
(1.06,10-200)\end{array}$ & $\begin{array}{l}33.90 \pm 16.86 \\
(3.68,20-78)\end{array}$ & $\begin{array}{l}37.10 \pm 16.84 \\
(2.85,12-85)\end{array}$ & $\begin{array}{l}34.14 \pm 15.24 \\
(5.76,17-61)\end{array}$ & $0.846^{\dagger}$ \\
\hline \multirow{2}{*}{ Stone opacity, n (\%) } & Radio-opaque & $229(80.3 \%)$ & $17(6.0 \%)$ & $32(11.2 \%)$ & $7(2.5 \%)$ & \multirow{2}{*}{$0.941^{\ddagger}$} \\
\hline & Radiolucent & $36(80.0 \%)$ & $4(8.9 \%)$ & $5(11.1 \%)$ & $0(0.0 \%)$ & \\
\hline \multirow{5}{*}{ Stone location, n (\%) } & One calyx & $55(77.5 \%)$ & $5(7.0 \%)$ & $9(12.7 \%)$ & $2(2.8 \%)$ & \multirow{5}{*}{$0.860^{\S}$} \\
\hline & Pelvis & $46(83.6 \%)$ & $6(10.9 \%)$ & $3(5.5 \%)$ & $0(0.0 \%)$ & \\
\hline & Upper ureter & $7(87.5 \%)$ & $0(0.0 \%)$ & $0(0.0 \%)$ & $1(12.5 \%)$ & \\
\hline & $\begin{array}{l}\text { Multiple } \\
\text { locations }\end{array}$ & $130(79.8 \%)$ & $9(5.5 \%)$ & $20(12.3 \%)$ & $4(2.4 \%)$ & \\
\hline & Staghorn & $27(81.8 \%)$ & $1(3.0 \%)$ & $5(15.2 \%)$ & $0(0.0 \%)$ & \\
\hline \multirow{2}{*}{ Staghorn stone, n (\%) } & Yes & $27(81.8 \%)$ & $1(3.0 \%)$ & $5(15.2 \%)$ & $0(0.0 \%)$ & \multirow{2}{*}{$0.847^{\ddagger}$} \\
\hline & No & $238(80.1 \%)$ & $20(6.7 \%)$ & $32(10.8 \%)$ & $7(2.4 \%)$ & \\
\hline \multirow{2}{*}{ Complex stones, n (\%) } & Yes & $157(80.1 \%)$ & $10(5.1 \%)$ & $25(12.8 \%)$ & $4(2.0 \%)$ & \multirow{2}{*}{$0.818^{\ddagger}$} \\
\hline & No & $108(80.6 \%)$ & $11(8.2 \%)$ & $12(9.0 \%)$ & $3(2.2 \%)$ & \\
\hline \multirow[t]{2}{*}{ Hydronephrosis, n (\%) } & $\begin{array}{l}\text { Moderate } \\
\text { or severe } \\
\text { (significant) }\end{array}$ & $171(88.1 \%)$ & $11(5.7 \%)$ & $7(3.6 \%)$ & $5(2.6 \%)$ & \multirow[t]{2}{*}{$<0.0001^{\ddagger}$} \\
\hline & Nil or Mild & $94(69.1 \%)$ & $10(7.3 \%)$ & $30(22.1 \%)$ & $2(1.5 \%)$ & \\
\hline \multirow{2}{*}{$\begin{array}{l}\text { Type of anesthesia, n } \\
(\%)\end{array}$} & General & $256(80.0 \%)$ & $20(6.2 \%)$ & $37(11.6 \%)$ & $7(2.2 \%)$ & \multirow{2}{*}{$0.377^{\ddagger}$} \\
\hline & Spinal & $9(90.0 \%)$ & $1(10.0 \%)$ & $0(0.0 \%)$ & $0(0.0 \%)$ & \\
\hline \multirow{2}{*}{ Kidney side, n (\%) } & Right & $136(80.0 \%)$ & $12(7.0 \%)$ & $20(11.8 \%)$ & $2(1.2 \%)$ & \multirow{2}{*}{$0.975^{\ddagger}$} \\
\hline & Left & $129(80.7 \%)$ & $9(5.6 \%)$ & $17(10.6 \%)$ & $5(3.1 \%)$ & \\
\hline \multirow{2}{*}{$\begin{array}{l}\text { Imaging for access, } \mathrm{n} \\
(\%)\end{array}$} & Fluoroscopy & $238(79.1 \%)$ & $19(6.3 \%)$ & $37(12.3 \%)$ & $7(2.3 \%)$ & \multirow{2}{*}{$0.054^{\ddagger}$} \\
\hline & Ultrasonography & $27(93.1 \%)$ & $2(6.9 \%)$ & $0(0.0 \%)$ & $0(0.0 \%)$ & \\
\hline \multirow{4}{*}{ Calyx for access, n (\%) } & $\begin{array}{l}\text { Upper calyx } \\
\text { group }\end{array}$ & $16(76.2 \%)$ & $1(4.8 \%)$ & $4(19.0 \%)$ & $0(0.0 \%)$ & \multirow{4}{*}{$0.019 \S$} \\
\hline & $\begin{array}{l}\text { Middle calyx } \\
\text { group }\end{array}$ & $64(83.1 \%)$ & $5(6.5 \%)$ & $6(7.8 \%)$ & $2(2.6 \%)$ & \\
\hline & $\begin{array}{l}\text { Lower calyx } \\
\text { group }\end{array}$ & $179(81.7 \%)$ & $12(5.5 \%)$ & $24(11.0 \%)$ & $4(1.8 \%)$ & \\
\hline & $\begin{array}{l}\text { Multiple calices } \\
\text { group }\end{array}$ & $6(46.1 \%)$ & $3(23.1 \%)$ & $3(23.1 \%)$ & $1(7.7 \%)$ & \\
\hline \multirow{2}{*}{ Number of tract, n (\%) } & Single tract & $247(82.3 \%)$ & $17(5.7 \%)$ & $30(10.0 \%)$ & $6(2.0 \%)$ & \multirow{2}{*}{$0.004^{\ddagger}$} \\
\hline & Multiple tracts & $18(60.0 \%)$ & $4(13.3 \%)$ & $7(23.4 \%)$ & $1(3.3 \%)$ & \\
\hline \multirow{2}{*}{$\begin{array}{l}\text { Nephrostomy tube } \\
\text { insertion, } \mathrm{n}(\%)\end{array}$} & Yes (standard) & $17(73.9 \%)$ & $1(4.4 \%)$ & $5(21.7 \%)$ & $0(0.0 \%)$ & \multirow{2}{*}{$0.404^{\ddagger}$} \\
\hline & No (tubeless) & $248(80.8 \%)$ & $20(6.5 \%)$ & $32(10.4 \%)$ & $7(2.3 \%)$ & \\
\hline \multicolumn{2}{|l|}{$\begin{array}{l}\text { Mean operative time } \\
\text { (SE, range), minute }\end{array}$} & $\begin{array}{l}56.37 \pm 29.80 \\
(1.89,10-195)\end{array}$ & $\begin{array}{l}61.39 \pm 32.30 \\
(7.61,15-120)\end{array}$ & $\begin{array}{c}62.41 \pm 21.04 \\
(3.61,20-110)\end{array}$ & $\begin{array}{l}47.50 \pm 18.64 \\
(7.61,20-75)\end{array}$ & $0.124^{\dagger}$ \\
\hline \multicolumn{2}{|c|}{$\begin{array}{l}\text { Mean postoperative hemoglobin } \\
\text { (SE, range), g/dL }\end{array}$} & $\begin{array}{c}12.49 \pm 1.60 \\
(0.10,8.1-16.4)\end{array}$ & $\begin{array}{c}12.61 \pm 1.95 \\
(0.42,9.0-16.5)\end{array}$ & $\begin{array}{c}9.47 \pm 1.33 \\
(0.22,7.0-13.7)\end{array}$ & $\begin{array}{c}11.00 \pm 2.36 \\
(0.96,8.0-14.0)\end{array}$ & $<0.0001^{\dagger}$ \\
\hline \multicolumn{2}{|c|}{$\begin{array}{l}\text { Mean postoperative hemoglobin drop } \\
\text { (SE, range), g/dL }\end{array}$} & $\begin{array}{c}1.02 \pm 1.04 \\
(0.06,0.0-7.5)\end{array}$ & $\begin{array}{c}1.13 \pm 1.06 \\
(0.23,0.0-3.1)\end{array}$ & $\begin{array}{c}2.92 \pm 1.72 \\
(0.29,0.0-6.7)\end{array}$ & $\begin{array}{c}2.55 \pm 2.74 \\
(1.12,0.0-7.4)\end{array}$ & $<0.0001^{\dagger}$ \\
\hline & Stone-free & $211(83.1 \%)$ & $13(5.1 \%)$ & $23(9.0 \%)$ & $7(2.8 \%)$ & \\
\hline Stone-free result, n (\%) & $\begin{array}{l}\text { Residual } \\
\text { fragments }\end{array}$ & $54(71.1 \%)$ & $8(10.5 \%)$ & $14(18.4 \%)$ & $0(0.0 \%)$ & $0.032^{\ddagger}$ \\
\hline
\end{tabular}

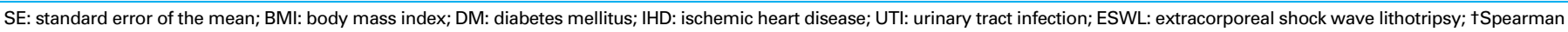
test; ‡Mann-Whitney test; §Kruskal-Wallis test.

access to the collecting system, stone manipulation and complication rate: vertebral column, pelvis and upper ureter anatomy, mobility of kidney, location of calyceal puncture, diameter of calyceal infundibulum, angle between calyces, angle between calyx tract with pelvis and long axis of kidney or vertebra, inflammation around ureteropelvic junction or upper ureteral stone, adequate visibility during access (in severe bleeding or complete space-occupying stone and stone fragments migration into other calyces. 


\begin{tabular}{|c|c|c|c|c|c|c|}
\hline Parameter & & Estimate & SE & $p$ value & OR & $95 \% \mathrm{Cl}$ of $\mathrm{OR}$ \\
\hline Postoperative hemoglobin & & -0.444 & 0.106 & $<0.0001$ & 0.64 & $0.52-0.79$ \\
\hline Postoperative hemoglobin drop & & 0.448 & 0.124 & $<0.0001$ & 1.57 & $1.23-2.00$ \\
\hline \multirow{2}{*}{ Renal dysfunction } & No & -1.125 & 0.504 & \multirow{2}{*}{0.026} & \multirow{2}{*}{0.32} & $0.12-0.87$ \\
\hline & Yes & 0 & & & & \\
\hline \multirow{2}{*}{ Anatomic upper urinary tract abnormality } & No & -3.085 & 0.734 & \multirow{2}{*}{$<0.0001$} & \multirow{2}{*}{0.05} & $0.01-0.19$ \\
\hline & Yes & 0 & & & & \\
\hline \multirow{2}{*}{ Significant (moderate-severe) hydronephrosis } & No & 0.841 & 0.331 & \multirow{2}{*}{0.011} & \multirow{2}{*}{2.32} & $1.21-4.43$ \\
\hline & Yes & 0 & & & & \multirow{3}{*}{$0.15-0.93$} \\
\hline \multirow{2}{*}{ Number of tract } & Single & -0.999 & 0.471 & \multirow{2}{*}{0.034} & \multirow{2}{*}{0.37} & \\
\hline & Multiple & 0 & & & & \\
\hline
\end{tabular}

SE: standard error of the mean; OR: odds ratio; $\mathrm{Cl}$ : confidence interval.

\section{Conclusion}

In complete supine PCNL, many complications were in the lower Clavien grades and major complications were uncommon. We found that renal dysfunction, upper urinary tract abnormality, significant hydronephrosis, multiple tracts, postoperative hemoglobin and hemoglobin drop predicted MCC complications.

Acknowledgments: The authors acknowledge that Dr. Siavash Falahatkar performed all PCNLs in this research.

Competing interests: Authors declare no competing financial or personal interests.

This paper has been peer-reviewed.

\section{References}

1. Mirheydar HS, Palazzi KL, Derweesh IH, et al. Percutaneous nephrolithotomy use is increasing in the United States: An analysis of trends and complications. J Endourol 2013;27:979-83. http://dx.doi. org/10.1089/end.2013.0104

2. Ghani KR, Sammon JD, Bhojani N, et al. Trends in percutaneous nephrolithotomy use and outcomes in the United States. J Urol 2013;190:558-64. http://dx.doi.org/10.1016/i.juro.2013.02.036

3. de la Rosette JJ, Zuazu JR, Tsakiris P, et al. Prognostic factors and percutaneous nephrolithotomy morbidity: A multivariate analysis of a contemporary series using the Clavien classification. J Urol 2008;180:2489-93. http://dx.doi.org/10.1016/i.juro.2008.08.025

4. Michel MS, Trojan L, Rassweiler JJ. Complications in percutaneous nephrolithotomy. Eur Urol 2007;51:899 906.

5. de la Rosette J, Assimos D, Desai M, et al. The Clinical Research Office of the Endourological Society Percutaneous Nephrolithotomy Global Study: Indications, complications, and outcomes in 5803 patients. J Endourol 2011;25:11-7. http://dx.doi.org/10.1089/end.2010.0424

6. Shin TS, Cho HJ, Hong SH, et al. Complications of percutaneous nephrolithotomy classified by the modified Clavien grading system: A single center's experience over 16 years. Korean I Urol 2011;52:769-75. http://dx.doi.org/10.4111/kju.2011.52.11.769

7. Seitz $C$, Desai $M$, Häcker $A$, et al. Incidence, prevention, and management of complications following percutaneous nephrolitholapaxy. Eur Urol 2012;61:146-58. http://dx.doi.org/10.1016/i. eururo.2011.09.016

8. Labate G, Modi P, Timoney A, et al. The percutaneous nephrolithotomy global study: Classification of complications. J Endourol 2011;25:1275-80. http://dx.doi.org/10.1089/end.2011.0067
9. Dindo D, Demartines N, Clavien PA. Classification of surgical complications: A new proposal with evaluation in a cohort of 6336 patients and results of a survey. Ann Surg 2004;240:205-13. http://dx.doi. org/10.1097/01.sla.0000133083.54934.ae

10. Tefekli A, Ali Karadag M, Tepeler K, et al. Classification of percutaneous nephrolithotomy complications using the modified Clavien grading system: Looking for a standard. Eur Urol 2008;53:184-90. http:// dx.doi.org/10.1016/i.eururo.2007.06.049

11. Morgan M, Smith N, Thomas K, et al. Is Clavien the new standard for reporting urological complications? BJU Int 2009;104:434-6. http://dx.doi.org/10.1111/i.1464-410X.2009.08516.x

12. de la Rosette JJ, Opondo D, Daels FP, et al. Categorisation of complications and validation of the Clavien score for percutaneous nephrolithotomy. Eur Urol 2012;62:246-55. http://dx.doi.org/10.1016/i. eururo.2012.03.055

13. Falahatkar S, Moghaddam AA, Salehi M, et al. Complete supine percutaneous nephrolithotripsy comparison with the prone standard technique. J Endourol 2008;22:2513-17. http://dx.doi.org/10.1089/ end.2008.0463

14. Falahatkar $S$, Neiroomand $H$, Akbarpour $M$, et al. One-shot versus metal telescopic dilation technique for tract creation in percutaneous nephrolithotomy: Comparison of safety and efficacy. J Endourol 2009;23:615-8. http://dx.doi.org/10.1089/end.2008.0330

15. El-Nahas AR, Eraky I, Shokeir AA, et al. Factors affecting stone-free rate and complications of percutaneous nephrolithotomy for treatment of staghorn stone. Urology 2012;79:1236-41. http://dx.doi. org/10.1016/i.urology.2012.01.026

16. Palmero JL, Nu-o de la Rosa I, Miralles J, et al. Study of predictive factors for complications after percutaneous nephrolithotomy according to the Clavien classification. Actas Urol Esp 2013;37:412-8. http:// dx.doi.org/10.1016/i.acuro.2012.11.006

17. Akman T, Binbay M, Akcay M, et al. Variables that influence operative time during percutaneous nephrolithotomy: An analysis of 1897 cases. J Endourol 2011;25:1269-73. http://dx.doi.org/10.1089/end.2011.0061

18. Rassweiler JJ, Rassweiler MC, Michel MS. Classification of complications: Is the Clavien-Dindo classification the gold standard? Eur Urol 2012;62:256-60. http://dx.doi.org/10.1016/i.eururo.2012.04.028

19. Turna $B$, Umul $M$, Demiryoguran $S$, et al. How do increasing stone surface area and stone configuration affect overall outcome of percutaneous nephrolithotomy? J Endourol 2007;21:34-43. http://dx.doi. org/10.1089/end.2005.0315

20. Olbert PJ, Hegele A, Schrader AJ, et al. Pre- and perioperative predictors of short-term clinical outcomes in patients undergoing percutaneous nephrolitholapaxy. Urol Res 2007;35:225-30. http://dx.doi. org/10.1007/s00240-007-0112-6

21. Onal B, Dogan HS, Satar N, et al. Factors affecting complication rates of percutaneous nephrolithotomy in children: Results of a multi-institutional retrospective analysis by the Turkish pediatric urology society. J Urol 2014;191:777-82. http://dx.doi.org/10.1016/i.juro.2013.09.061

22. Duvdevani $M$, Nott $L$, Ray AA, et al. Percutaneous nephrolithotripsy in patients with diabetes mellitus. J Endourol 2009;23:21-6. http://dx.doi.org/10.1089/end.2008.0282

23. Kurtulus FO, Fazlioglu A, Tandogdu Z, et al. Percutaneous nephrolithotomy: Primary patients versus patients with history of open renal surgery. J Endourol 2008;22:2671-5. http://dx.doi.org/10.1089/ end.2007.0431

24. Yuruk E, Tefekli A, Sari E, et al. Does previous extracorporeal shock wave lithotripsy affect the performance and outcome of percutaneous nephrolithotomy? J Urol 2009;181:663-7. http://dx.doi.org/10.1016/i. juro.2008.10.016

25. Resorlu B, Kara C, Senocak C, et al. Effect of previous open renal surgery and failed extracorporeal shockwave lithotripsy on the performance and outcomes of percutaneous nephrolithotomy. J Endourol 2010;24:13-6. http://dx.doi.org/10.1089/end.2009.0291 
Falahatkar et al.

26. Mariappan P, Smith G, Bariol SV, et al. Stone and pelvic urine culture and sensitivity are better than bladder urine as predictors of urosepsis following percutaneous nephrolithotomy: A prospective clinical study. J Urol 2005;173:1610-4. http://dx.doi.org/10.1097/01.ju.0000154350.78826.96

27. Chen $L, X \cup Q Q$, Li JX, et al. Systemic inflammatory response syndrome after percutaneous nephrolithotomy: An assessment of risk factors. Int J Urol 2008;15:1025-8. http://dx.doi.org/10.1111/i.14422042.2008.02170.x

28. Darenkov AF, Derevianko II, Martov AG, et al. The prevention of infectious-inflammatory complications in the postoperative period in percutaneous surgical interventions in patients with urolithiasis. Urol Nefrol 1994:2:24-6.

29. Yaycioglu 0, Egilmez T, Gul U, et al. Percutaneous nephrolithotomy in patients with normal versus impaired renal function. Urol Res 2007;35:101-5. http://dx.doi.org/10.1007/s00240-007-0081-9

30. Sairam K, Scoffone CM, Alken P, et al. Percutaneous nephrolithotomy and chronic kidney disease: Results from the CROES PCNL Global Study. J Urol 2012;188:1195-200. http://dx.doi.org/10.1016/i. juro.2012.06.027

31. Osther PJ, Razvi H, Liatsikos E, et al. Percutaneous nephrolithotomy among patients with renal anomalies: Patient characteristics and outcomes; a subgroup analysis of the clinical research office of the endourological society global percutaneous nephrolithotomy study. J Endourol 2011;25:1627-32. http://dx.doi. org/10.1089/end.2011.0146

32. Rais-Bahrami S, Friedlander Il, Duty BD, et al. Difficulties with access in percutaneous renal surgery. Ther Adv Urol 2011;3:59-68. http://dx.doi.org/10.1177/1756287211400661

33. Lojanapiwat $B$. The ideal puncture approach for PCNL: Fluoroscopy, ultrasound or endoscopy? Indian J Urol 2013;29:208-13. http://dx.doi.org/10.4103/0970-1591.117284

34. Xue W, Pacik W, Boellaard W, et al. Management of single large nonstaghorn renal stones in the CROES PCNL global study. J Urol 2012;187:1293-7. hittp://dx.doi.org/10.1016/i.juro.2011.11.113

35. Cicek $T$, Gonulalan U, Dogan R, et al. Spinal anesthesia is an efficient and safe anesthetic method for percutaneous nephrolithotomy. Urology 2014;83:50-5. http://dx.doi.org/10.1016/j.urology.2013.08.064

36. Mehrabi S, Mousavi Zadeh A, Akbartabar Toori M, et al. General versus spinal anesthesia in percutaneous nephrolithotomy. Urol J 2013;10:756-61

37. Nouralizadeh A, Ziaee SA, Hosseini Sharifi SH, et al. Comparison of percutaneous nephrolithotomy under spinal versus general anesthesia: A randomized clinical trial. J Endourol 2013;27:974-8. http://dx.doi. org/10.1089/end.2013.0145
38. Falahatkar $S$, Neiroomand $H$, Enshaei $A$, et al. Totally ultrasound versus fluoroscopically guided complete supine percutaneous nephrolithotripsy: A first report. J Endourol 2010;24:1421-6.

39. Basiri A, Ziaee AM, Kianian HR, et al. Ultrasonographic versus fluoroscopic access for percutaneous nephrolithotomy: A randomized clinical trial. J Endourol 2008;22:281-4. http://dx.doi.org/10.1089/ end.2007.0141

40. Falahatkar $S$, Moghaddam KG, Kazemnezhad E, et al. Factors affecting operative time during percutaneous nephrolithotomy: Our experience with the complete supine position. J Endourol 2011;25:1831-6. http:// dx.doi.org/10.1089/end.2011.0278

41. Aron $M$, Goel R, Kesarwani PK, et al. Upper pole access for complex lower pole renal calculi. BJU Int 2004;94:849-52; discussion 852. http://dx.doi.org/10.1111/i.1464-410X.2004.05045.x

42. Falahatkar $\mathrm{S}$, Kazemnezhad E, Moghaddam KG, et al. Middle calyx access in complete supine percutaneous nephrolithotomy. Can Urol Assoc J 2013;7:E306-10. http://dx.doi.org/10.5489/cuaj.11307

43. Ni S, Qivin C, Tao W, et al. Tubeless percutaneous nephrolithotomy is associated with less pain and shorter hospitalization compared with standard or small bore drainage: A meta-analysis of randomized, controlled trials. Urology 2011;77:1293-8. http://dx.doi.org/10.1016/j.urology.2010.10.023

44. Hegarty NJ, Desai MM. Percutaneous nephrolithotomy requiring multiple tracts: Comparison of morbidity with single-tract procedures. J Endourol 2006;20:753-60. http://dx.doi.org/10.1089/ end.2006.20.753

45. Netto NR Jr, Ikonomidis J, Ikari 0 , et al. Comparative study of percutaneous access for staghorn calculi. Urology 2005;65:659-62; discussion 662-3. http://dx.doi.org/10.1016/j.urology.2004.10.081

46. Turna B, Nazli 0, Demiryoguran $S$, et al. Percutaneous nephrolithotomy: Variables that influence hemorrhage. Urology 2007;69:603-7. http://dx.doi.org/10.1016/j.urology.2006.12.021

47. Akman $T$, Binbay $M$, Sari $E$, et al. Factors affecting bleeding during percutaneous nephrolithotomy: Single surgeon experience. J Endourol 201 1;25:327-33. http://dx.doi.org/10.1089/end.2010.0302

Correspondence: Dr. Keivan Gholamiani Moghaddam, Urology Research Center, Guilan University of Medical Sciences, Rasht, Iran; keivan_ghm@yahoo.com 